Supporting Information

\title{
STABILITY OF IONIC MAGNETIC SURFACTANTS IN AQUEOUS SOLUTIONS: MEASUREMENT TECHNIQUES AND IMPACT ON MAGNETIC PROCESSES
}

Alex Fortenberry, Derek Reed, Adam Smith, Paul Scovazzo*

Corresponding Author Email: scovazzo@olemiss.edu 


\section{- CMC Characterization:}

The following data are surface tension vs. concentration measurements of various magnetic and nonmagnetic surfactants in water. The surfactants include $\mathrm{C}_{16} \mathrm{TABr}, \mathrm{MnDDS}, \mathrm{C}_{16} \mathrm{TAFeCl} \mathrm{Br}_{3}, \mathrm{C}_{16} \mathrm{TAGdCl}_{3} \mathrm{Br}$ and SDS. The $\mathrm{CMC}$ values reported in the main body of the manuscript for these compounds were obtained from the surface tension measurements discussed below.

The measurements were obtained from a Sigma 700/701 Biolin Scientific Force Tensiometer using a platinum Du Nouy ring. The Du Nouy ring was cleaned with ethanol and DI water and placed inside a flame until red hot between each measurement. Table S1 summarizes the data from figures S1-S4

Table S1: CMC values for various surfactants examined in this study

\begin{tabular}{cc} 
Surfactant & $\begin{array}{c}\mathrm{CMC} \\
(\mathrm{mM})\end{array}$ \\
\hline $\mathrm{C}_{16} \mathrm{TABr}$ & 1 \\
$\mathrm{MnDDS}$ & 1.4 \\
$\mathrm{C}_{16} \mathrm{TAFeCl}_{3} \mathrm{Br}$ & 0.6 \\
$\mathrm{C}_{16} \mathrm{TAGdCl}_{3} \mathrm{Br}$ & 0.8 \\
$\mathrm{SDS}$ & 8.2
\end{tabular}

C16TABr:

The CMC of $\mathrm{C}_{16} \mathrm{TABr}$ was found to be $1.0 \mathrm{mM}$ 


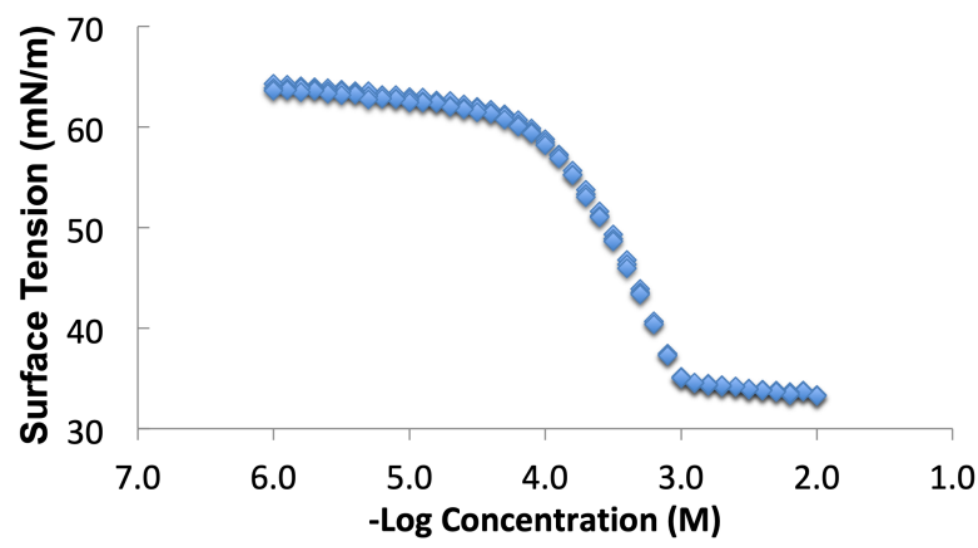

Figure S1: Surface tension vs. concentration measurements of $\mathrm{C}_{16} \mathrm{TABr}$ in water.

SDS:

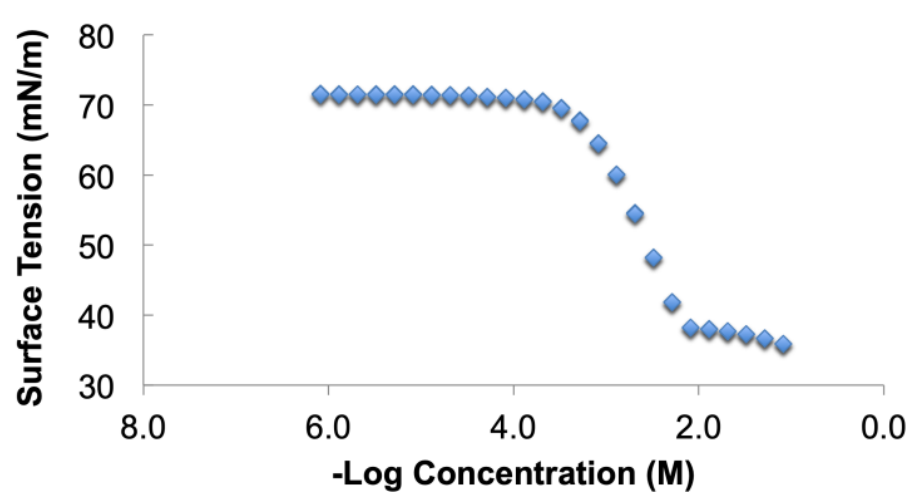

Figure S2: Surface tension vs. concentration measurements of SDS in water.

MnDDS:

The CMC of this surfactant, was determined to be $1.4 \mathrm{mM}$ (Figure S2), which is in close agreement with a value found in the literature of $1.2 \mathrm{mM}$ 


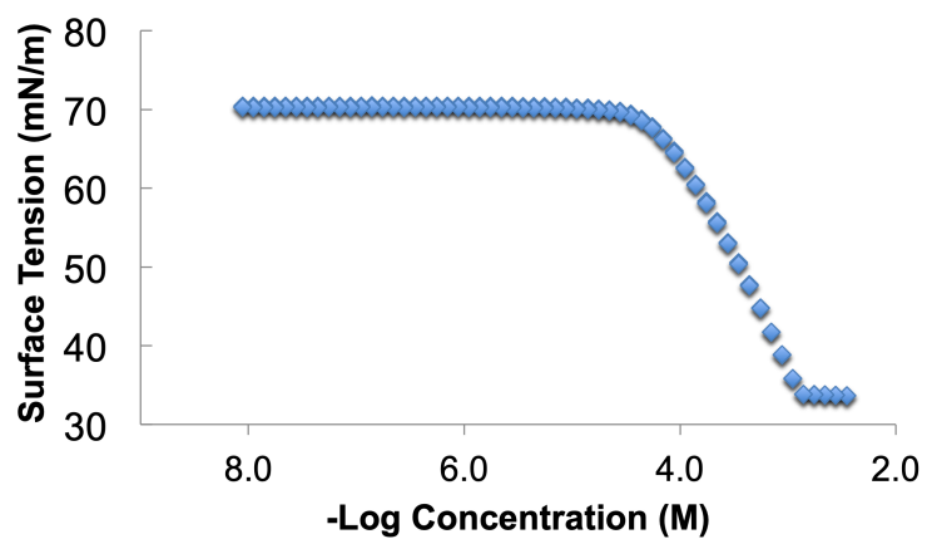

Figure S3: Surface tension vs. concentration measurements of MnDDS in water.

$\mathrm{C}_{16} \mathrm{TAFeCl}_{3} \mathrm{Br}$ :

The $\mathrm{CMC}$ of $\mathrm{C}_{16} \mathrm{TAFeCl}_{3} \mathrm{Br}$ was found to be $0.6 \mathrm{mM}$.

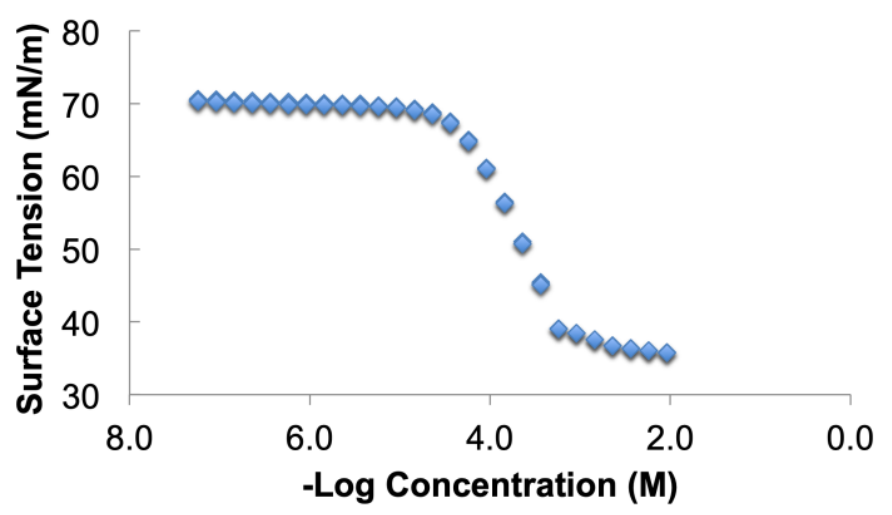

Figure S4: Surface tension vs. concentration measurements of $\mathrm{C}_{16} \mathrm{TAFeCl}{ }_{3} \mathrm{Br}$ in water.

\section{$\mathrm{C}_{16} \mathrm{TAGdCl}_{3} \mathrm{Br}$ :}

The $\mathrm{CMC}$ of $\mathrm{C}_{16} \mathrm{TAGdCl}_{3} \mathrm{Br}$ was investigated and found to be $0.8 \mathrm{mM}$ 


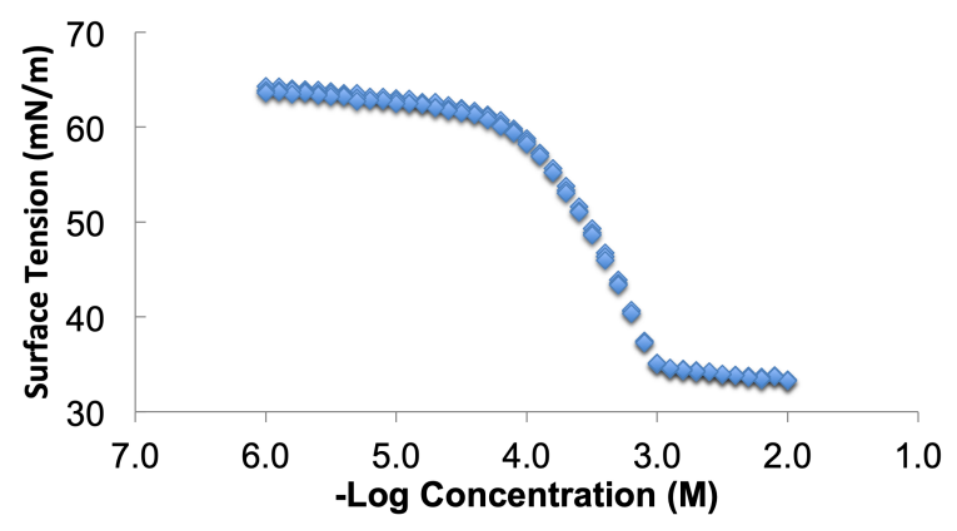

Figure S5: Surface tension vs. concentration measurements of $\mathrm{C}_{16} \mathrm{TAGdCl}_{3} \mathrm{Br}$ in water.

- Specific Conductivity vs. Concentration:

This data provides CMC information for MnDDS and $\mathrm{C}_{16} \mathrm{TABr}$ for comparison to the CMC data obtained from surface tension measurements. The CMC was taken to be the point in the graph that experienced the greatest change in slope with increasing surfactant concentration. As shown below, this data is in agreement with the surface tension data.

\section{MnDDS:}

The CMC was found to be approx. $1.4 \mathrm{mM}$, which is in agreement with the surface tension measurements of Figure S3. 


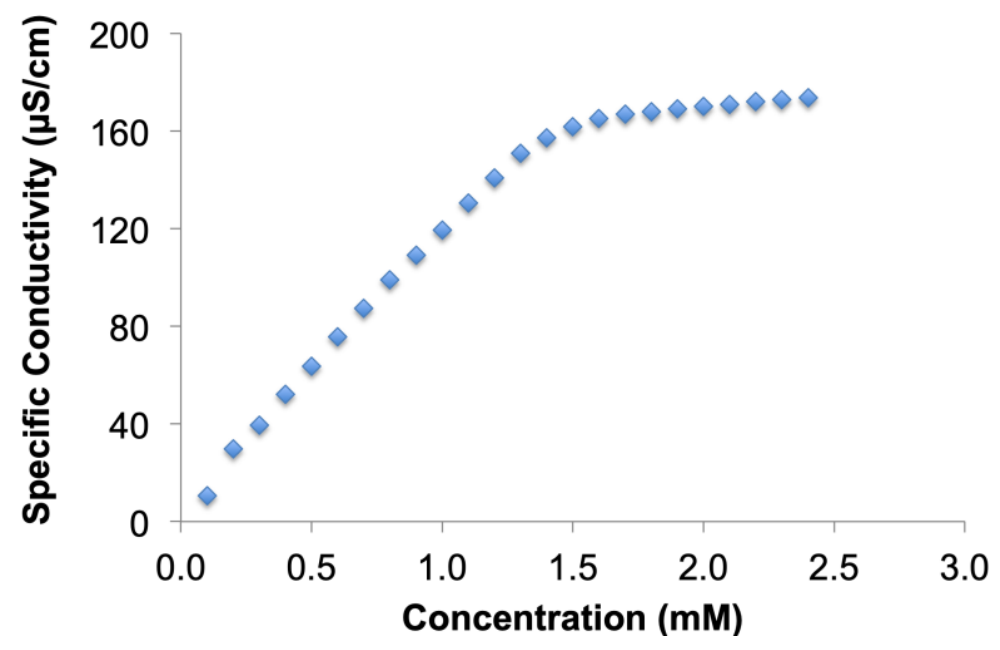

\section{C16TABr:}

The CMC was found to be approx. $1.0 \mathrm{mM}$, which is in agreement with the surface tension measurements of Figure S1.

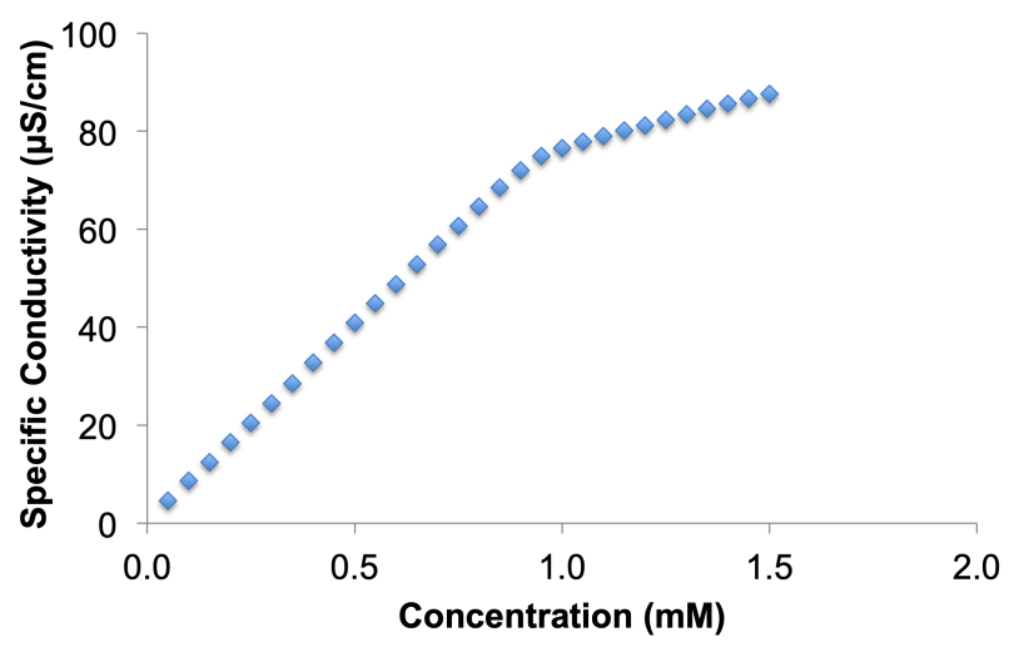

